\title{
APLIKASI PENERIMAAN SISWA BARU BERBASIS WEB
}

\author{
Iis Ariska ${ }^{1)}$ \\ ${ }^{1,}$ Manajemen Informatika, Politeknik Bina Budaya Citra Jl. Balandongan Jalur Lingkar Selatan No. 23 Kota Sukabumi \\ e-mail: Iisariska@bbc.ac.id, \\ * Korespondensi: e-mail: lisariska@bbc.ac.id,
}

\begin{abstract}
ABSTRAK
Penerimaan siswa baru merupakan salah satu proses yang ada di instansi pendidikan seperti sekolah. Pada umumnya proses penerimaan siswa baru dilakukan melalui tahapan pendaftaran, tes seleksi, dan pengumuman penerimaan siswa. Dalam penelitian ini penerapannya pada SMK Yaspim Gegerbitung Kabupaten Sukabumi yang selama ini dilakukan belum sepenuhnya termanfaatkan secara maksimal hanya sebatas menggunakan pengolahan kata dan angka, yang memungkinkan kesulitan menyimpan data dan mencari data-data siswa yang baru, belum lagi data-data yang sering hilang dan berkas yang berceceran dimana-mana

Oleh sebab itu penulis mengambil masalah di bidang penerimaan siswa itu sendiri. Dengan ini di harapkan dapat membantu sekolah untuk meningkatkan pelayanan penerimaan siswa baru serta untuk menyimpan data atau dokumen penting lainnya yang harus di simpan dengan baik, cepat dan akurat. Metode penelitian yang digunakan adalah Observasi lapangan, wawancara, studi pustaka. Aplikasi penerimaan siswa baru ini dibangun dengan bahasa pemrograman PHP serta memanfaatkan database MySQL sebagai database server.

Hasil dari penelitian ini adalah Aplikasi penerimaan siswa baru berbasis web yang memiliki kemampuan memberikan kemudahan agar para siswa dan orang tua siswa tidak perlu bersusah payah mendatangi sekolah untuk sekedar melihat pengumuman atau informasi yang berkaitan dengan pelaksanaan Penerimaan Siswa Baru.
\end{abstract}

Kata Kunci: Siswa, MYSQL, Peneriman

\begin{abstract}
Admission of new students is one of the processes that exist in educational institutions such as schools. In general, the admission process of new students is carried out through the stages of registration, selection tests, and announcements of admissions. In this study its application to SMK Yaspim Gegerbitung Sukabumi regency that has been done has not been fully utilized to the maximum only limited to using word and number processing, which allows difficulty storing data and searching for new student data, not to mention often lost data and scattered files everywhere

Therefore the author takes issue in the field of admissions itself. This is expected to help schools to improve the admissions services of new students and to store important data or documents that must be stored properly, quickly and accurately. The research methods used are field observation, interviews, library studies. This new student application is built with PHP programming language and utilizes MySQL database as database server.

The result of this study is a web-based new student admission application that has the ability to provide convenience so that students and parents do not have to bother visiting the school to just see announcements or information related to the implementation of New Student Admissions.
\end{abstract}

Keywords: Student, MYSQL, Receiver 


\section{Pendahuluan}

Perkembangan sistem informasi pada era globalisasi seperti sekarang ini sangatlah dirasa penting karena saat ini suatu instansi atau perusahaan tidak terlepas dari penggunaan komputer sebagai alat bantu pengolahan data yang canggih. Teknologi informasi tidak dapat dipisahkan dengan perkembangan peradaban manusia. Perkembangan teknologi informasi juga berpengaruh pada bidang pendidikan. Perkembangan ini dapat dilihat pada satuan-satuan kerja pada instansi yang sudah terkomputerisasi. Saat ini belum banyak sekolah di Indonesia menyelenggarakan Penerimaan Siswa Baru secara online. Dengan manfaat dan kemudahan yang ada, sudah seharusnya sistem ini dikembangkan oleh tiap-tiap sekolah.

Hal ini sejalan dengan kemajuan teknologi informasi dan komunikasi seperti teknologi internet yang mampu mendukung proses input dan output data secara cepat dan akurat, khususnya dalam pelaksanaan Penerimaan Siswa Baru. Sekarang ini masih banyak sekolah yang belum menggunakan teknologi sistem informasi dalam menangani permasalahan-permasalahannya. Seperti pada pelayanan pada saat Penerimaan Siswa Baru, serta proses pembuatan laporan, semua masih bersifat manual. Seperti yang terjadi di SMK Yaspim Gegerbitung Kabupaten Sukabumi, proses-proses pendataannya dirasakan masih kurang maksimal dan belum sepenuhnya memanfaaatkan teknologi sistem informasi.

Dikembangkannya sistem Penerimaan Siswa Baru secara online di sekolah-sekolah ini diharapkan akan membuat pelaksanaan Penerimaan Siswa Baru menjadi lebih mudah. Selain itu, sistem ini akan menjadikan proses pendataan dan administrasi lebih mudah dan cepat. Pelaksanaan Penerimaan Siswa Baru akan menjadi lebih efisien, baik dalam hal waktu, tempat, biaya, maupun tenaga. Tak ketinggalan juga, dengan sistem ini, para peserta dan orang tua peserta tidak perlu bersusah payah mendatangi sekolah untuk sekedar melihat pengumuman atau informasi yang berkaitan dengan pelaksanaan Penerimaan Siswa Baru.

\section{Tinjauan Pustaka}

Menurut Suci Purnama (2011;234) "Penerimaan Siswa Baru adalah adalah sistem sekolah yang mengelola data calon siswa baru dengan cara memasukkan data tersebut ke dalam sistem dan menghasilkan laporan data calon siswa". Menurut Sutejo $(2006 ; 2)$ "Pengertian penerimaan disini pada dasarnya hanya untuk memperlancar dan mempermudah dalam proses pendaftaran siswa siswi baru, pendataan dan pembagian kelas seorang siswa siswi. Aplikasi merupakan suatu subkelas perangkat lunak komputer yang memanfaatkan kemampuan komputer langsung untuk melakukan suatu tugas yang diinginkan pengguna. Biasanya dibandingkan dengan perangkat lunak sistem yang mengintegrasikan berbagai kemampuan komputer.

Menurut Simarmata $(2010 ; 185)$, "Aplikasi berbasis web adalah sistem perangkat lunak yang berdasarkan pada teknologi dan standar World Wide Web Consortium (W3C). Mereka menyediakan sumber daya web spesifik seperti konten dan layanan melalui sebuah antarmuka pengguna dan browser web.

Menurut Lia Kuwayatno $(2015 ; 122)$ "Web browser ialah perangkat lunak yang fungsinya untuk membuka website dengan cara menuliskan alamat situs yang dituju pada kotak address". Menurut Smitdev Pahala $(2014 ; 78)$ "Berpendapat bahwa web browser merupakan lawan kata dari server yang tugasnya untuk menampilkan halaman website".

Menurut Asropudin (2013;109), "Web adalah sebuah kumpulan halaman yang diawali dengan halaman muka yang berisikan informasi, iklan, serta program aplikasi".

Menurut Ardhana (2012;3), "Web adalah suatu layanan sajian informasi yang menggunakan konsep hyperlink, yang memudahkan surfer (sebutan para pemakai komputer yang melakukan browsing atau penelusuran informasi melalui internet). Dari pengertian diatas penulis menyimpulkan Web adalah suatu layanan atau kumpulan halaman yang berisi informasi, iklan, serta program aplikasi yang dapat digunakan oleh surfer".

Menurut Simarmata (2010;185), “Aplikasi berbasis web adalah sistem perangkat lunak yang berdasarkan pada teknologi dan standar World Wide Web Consortium (W3C). Mereka menyediakan sumber daya web spesifik seperti konten dan layanan melalui sebuah antarmuka pengguna dan browser web.

Karakteristik ini dimasukan kedalam empat dimensi yang berbeda yang berisikan produk perangkat lunak 
Hal 1 -13 ISSN. P: 2715-1875, E: 2715-1883

itu sendiri, evolusi, dan penggunaan yang terhubung dengan cross cutting. Perlu ditekankan di sini bahwa kita tidak mengakui bahwa masing-masing karakteristik ini unik untuk pengembangan Aplikasi Web yang tidak pernah terjadi ketika pengembangan tradisional"

Aplikasi merupakan suatu subkelas perangkat lunak komputer yang memanfaatkan kemampuan komputer langsung

untuk melakukan suatu tugas yang diinginkan pengguna. Biasanya dibandingkan dengan perangkat lunak sistem yang

mengintegrasikan berbagai kemampuan komputer.

Terdapat beberapa teori yang mendefinisikan Aplikasi yang dikemukakan oleh beberapa para ahli, diantaranya adalah :

a. Menurut Hengky W. Pramana $(2016 ; 17)$ "Aplikasi adalah satu unit perangkat lunak yang dibuat untuk melayani kebutuhan akan beberapa aktivitas seperti sistem perniagaan, game, pelayanan masyarakat, periklanan, atau semua proses yang hampir dilakukan manusia”.

b. Menurut Shelly, Cashman, Verman (2015;57) “Aplikasi adalah seperangkat instruksi khusus dalam komputer yang dirancang agar kita menyelesaikan tugas-tugas tertentu".

c. Menurut Dhanta $(2015 ; 32)$, "Aplikasi adalah software yang dibuat oleh suatu perusahaan komputer untuk mengerjakan tugas-tugas tertentu".

Software komputer terbagi menjadi 2 yaitu :

1) Application Software

Mengarahkan kinerja penggunaan tertentu atau aplikasi komputer untuk memenuhi kebutuhan pengolahan informasi dari pengguna. Contoh : word processing.

2) System software

Mengendalikan dan mendukung operasi dari sistem komputer karena melakukan berbagai tugas pengolahan informasi. Contoh : operating system, network management, database management.

(O’Brien 2017;124)

Menurut Muhsin (2010;69) "Data adalah sekumpulan fakta, keterangan atau informasi mentah yang tidak terorganisir, berupa angka, simbol, kata-kata, atau sifat yang diperoleh melalui proses pengamatan atau pencarian ke sumber-sumber tertentu. Data menjadi berguna setelah diproses, ditafsirkan, diorganisir, disusun atau disajikan sehingga dapat dimengerti oleh orang yang menerimanya. Sekelompok data dapat diolah dan diproses lebih lanjut menjadi bentuk yang lebih kompleks, seperti informasi atau database, sehingga data dan informasi merupakan dua hal yang saling berkaitan. Secara bahasa, kata "data" berasal dari kata Latin tunggal "datum" yang artinya hal atau sesuatu yang diberikan. Dengan kata lain, data diberikan atau dihasilkan sebagai hasil pengamatan atau pengukuran dan harus diproses atau diolah terlebih dahulu untuk menghasilkan suatu informasi yang dapat memberikan arti dan bermanfaat".

Menurut Zulkifli A.M (2014;110) "Pengertian data adalah suatu keterangan, fakta atau bukti tentang suatu kenyataan yang masih mentah (original) dan belum diolah".

Menurut Arikunto (2015;70) "Definisi data adalah semua fakta dan angka-angka yang dapat dijadikan sebagai bahan untuk menyusun sebuah informasi

\section{METODE}

a. Teknik pengumpulan data merupakan langkah yang paling strategis [9].

b. Metode Observasi (Observation)

Kegiatan ini dimaksudkan untuk secara langsung melakukan pengamatan dan peninjauan yang dilakukan oleh penulis pada Dinas Pengendalian Penduduk dan Keluarga Berencana Kabupaten Sukabu- 
Hal 1 -13 ISSN. P: 2715-1875, E: 2715-1883

mi, sehingga memperoleh informasi yang jelas berkaitan dengan kegiatan yang dilakukan pada DPPKB Kabupaten Sukabum [10].

c. Metode wawancara (Interview)

Metode ini adalah pengumpulan data melalui tanya jawab yang dilakukan penulis kepada bagian staff pendistribusian Alat dan Obat Kontrasepsi DPPKB Kabupaten Sukabumi secara langsung [11].

d. Metode Studi Pustaka (library Research)

Metode studi pustaka digunakan agar mendapatkan sumber referensi yang baik berupa buku maupun artikel di internet untuk memperoleh bahan tentang perancangan program yang baik yang berhubungan dengan tugas akhir yang penulis buat [12].

e. Desain Pengembangan Sistem

Model SDLC (software Development Life Cycle) air terjun (waterfall) sering juga disebut model sekuensial linier (sequential linear) atau alur hidup klasik (classic life cycle). Model air terjun menyediakan pendekatan air hidup perangkat lunak secara sekuensial atau berurutan dimulai dari analisis, desain, pengkodean, pengujian, dan tahap pendukung (support) [8].

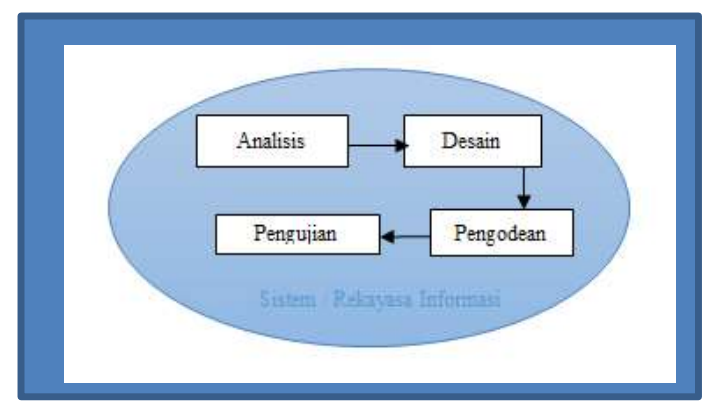

Gambar 1 Ilustrasi model waterfall

1. Analisis kebutuhan perangkat lunak

Proses pengumpulan kebutuhan dilakukan secara intensif untuk menspesifikasikan kebutuhan perangkat lunak agar dapat dipahami perangkat lunak seperti apa yang dibutuhkan oleh user. Spesifikasi kebutuhan perangkat lunak pada tahap ini perlu didokumentasikan [13].

2. Desain

Desain perangkat lunak adalah proses multilangkah yang fokus pada desain pembuatan program perangkat lunak termasuk struktur data, arsitektur perangkat lunak, representatif antarmuka, dan prosedur pengkodean. Tahap ini mentranslasi kebutuhan perangkat lunak dari tahap analisis kebutuhan ke representasi desain agar dapat diimplementasikan menjadi program pada tahap selanjutnya. Desain perangkat lunak yang dihasilkan pada tahap ini juga perlu didokumentasikan [14].

3. Pembuatan kode program

Desain harus ditranslasikan ke dalam program perangkat lunak. Hasil dari tahap ini adalah program komputer sesuai dengan desain yang telah dibuat pada tahap desain [16].

4. Pengujian

Pengujian fokus pada perangkat lunak secara dari segi logik dan fungsional dan memastikan bahwa semua bagian sudah diuji. Hal ini dilakukan untuk meminimalisir kesalahan (error) dan memastikan keluaran yang dihasilkan sesuai dengan yang diinginkan [15].

5. Pendukung (support) atau pemeliharaan (maintenance)

Tidak menutup kemungkinan sebuah perangkat lunak mengalami perubahan ketika sudah dikirimkan ke user. Perubahan bisa terjadi karena adanya kesalahan yang muncul dan tidak terdeteksi saat pengujian atau perangkat lunak harus beradaptasi dengan lingkungan baru. Tahap pendukung atau pemeliharaan dapat mengulang proses pengembangan mulai dari analisis spesifikasi untuk perubahan perangkat lunak yang sudah ada, tapi tidak untuk membuat perangkat lunak baru.

\section{Kelebihan Metode Waterfall}

Metode ini memungkinkan untuk departementalisasi dan kontrol. Proses pengembangan model fase one by one, sehingga meminimalisir kesalahan yang mungkin akan terjadi. Pengembangan bergerak dari konsep, yaitu melalui desain, implementasi, pengujian, instalasi, penyelesaian masalah, dan berakhir di operasi dan pemeliharaan. 
Hal 1 -13 ISSN. P: 2715-1875, E: 2715-1883

Kekurangan Metode Waterfall

Kekurangan menggunakan metode waterfall adalah metode ini tidak memungkinkan untuk banyak revisi jika terjadi kesalahan dalam prosesnya. Karena setelah aplikasi ini dalam tahap pengujian, sulit untuk kembali lagi dan mengubah sesuatu yang tidak terdokumentasikan dengan baik dalam tahap konsep sebelumnya [18].

\section{Hasil Dan Pembahasan}

\section{Analisa Sistem Yang Sedang Berjalan Pada Use Case Diagram}

Untuk menganalisa sistem yang sedang berjalan pada penelitian ini digunakan program Visual Paradigma untuk menggambarkan Use Case Diagram, Activity Diagram.

Sebuah Use case mempresentasikan sebuah interaksi antara aktor dengan sistem, use case diagram menggambarkan fungsionalitas yang diharapkan dari sebuah sistem yang ditentukan adalah "apa" yang diperbuat sistem dan bukan "bagaimana".

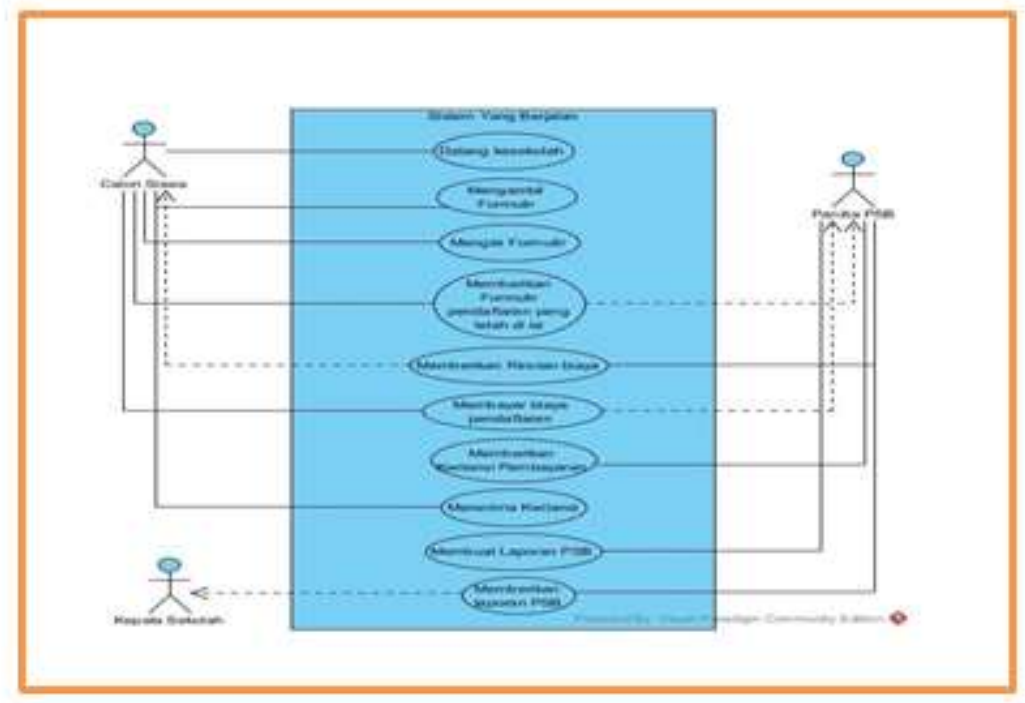

Gambar 2. Use Case Diagram Yang Sedang Berjalan Saat Ini

\section{a. Diagram Use Case User Yang Diusulkan}

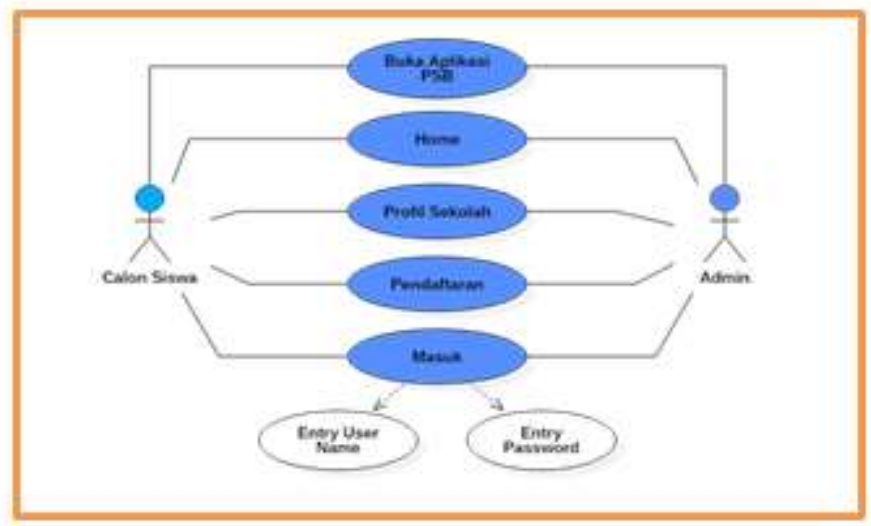

Gambar 3. Use Case User Yang Diusulkan 
b. Activity Diagram Yang Diusulkan

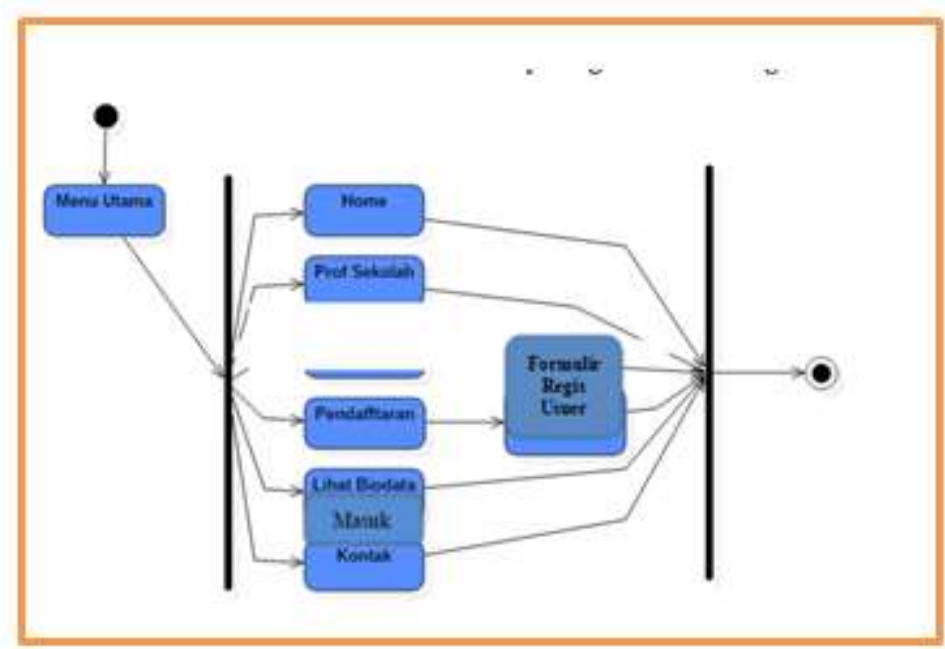

Gambar 4. Activity Diagram User Yang Diusulkan

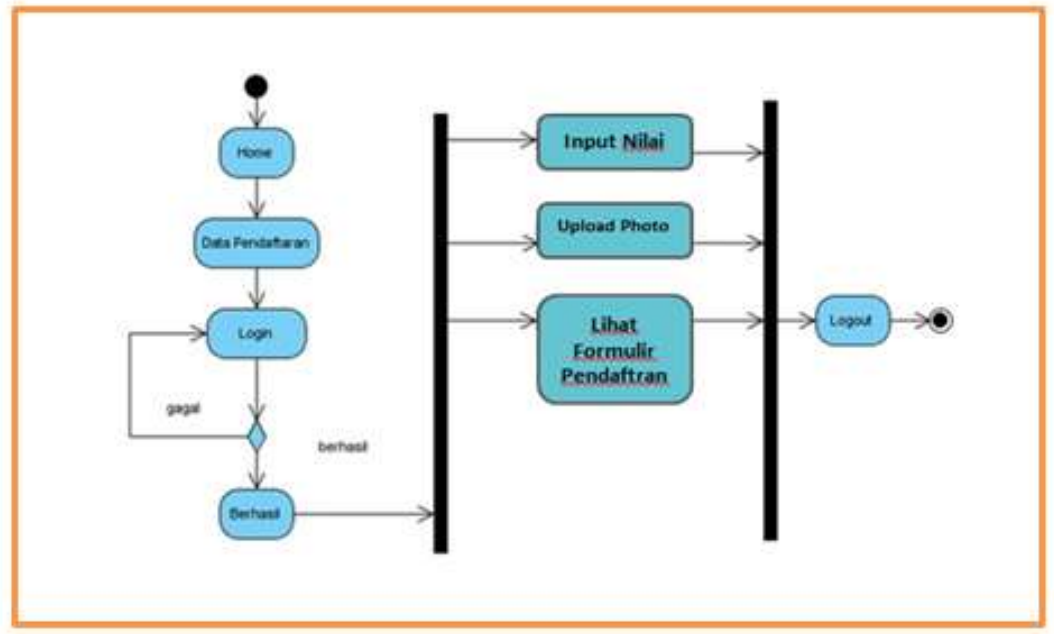

Gambar 5. Activity Diagram User Yang Diusulkan

\section{Spesifikasi Basis Data}

a. Tabel User

Nama Basis Data : Pendaftaran

Nama Tabel : users

Primary Key : id

Struktur : id, nama, username, password, level 
Hal 1 -13 ISSN. P: 2715-1875, E: 2715-1883

Tabel 1. Stuktur Tabel User

\begin{tabular}{|l|l|l|l|l|}
\hline No & Nama Field & Jenis & Lebar & Keterangan \\
\hline 1 & Id & int & 11 & No Pendaftaran \\
\hline 2 & nama & varchar & 45 & Nama Lengkap \\
\hline 3 & username & varchar & 100 & Alamat Email \\
\hline 4 & password & varchar & 225 & Password Email \\
\hline 5 & level & varchar & 45 & User / Admin \\
\hline
\end{tabular}

\section{c. Perancangan Interface}

Setelah Perancangan diagram dan database telah dibuat, maka selanjutnya adalah rancangan user interface sebagai berikut :

a. Perancangan Tampilan Home

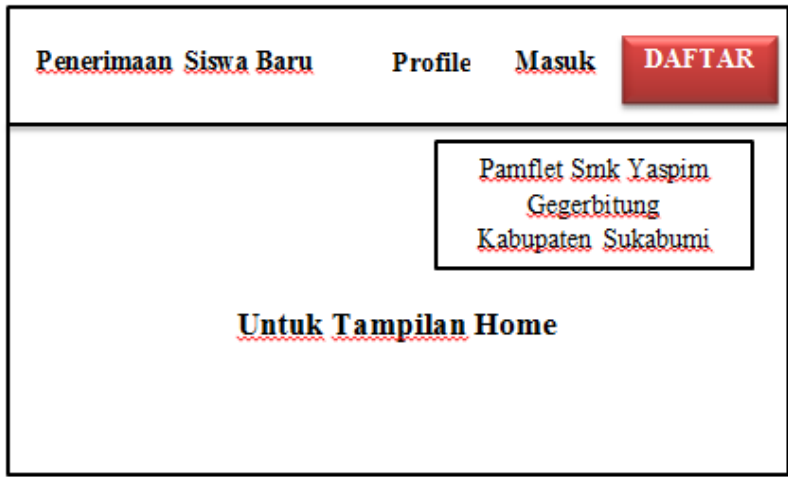

Gambar 6. Perancangan Tampilan Home

b. Perancangan Tampilan Form Registrasi Siswa

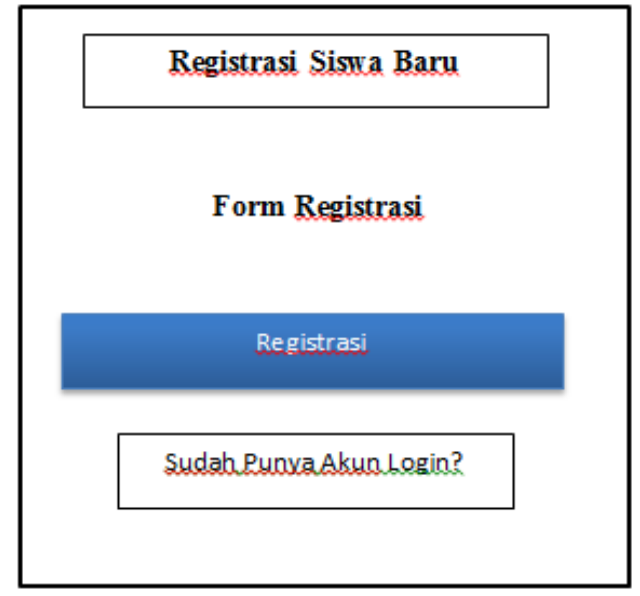

Gambar 7. Perancangan Tampilan Form Registrasi Siswa 


\section{Batasan Sistem}

Dalam pembatasan aplikasi tentu mempunyai batasan yang sudah ditentukan, adapaun batasannya adalah sebagai berikut :

b. Program Aplikasi yang dibuat hanya untuk masalah sekitar ruang lingkup pendaftaran siswa baru di SMK Yaspim Gegerbitung Kabupaten Sukabumi.

c. Output mencetak biodata calon siswa baru

\section{Perancangan Kebutuhan Sumber Daya}

Pada dasarnya kebutuhan sumberdaya manusia yang direncanakan untuk menerima masukan, menjalankan proses, menyimpan dan menggunakan data, menghasilkan, mengirimkan keluaran dan membantu pengendalian dari sistem secara keseluruhan terbagi menjadi tiga macam sumber daya yaitu :

a. Perangkat Lunak

Perangkat lunak yaitu perangkat yang digunakan untuk mengaktifkan fungsi dari perangkat keras dan dasar pemilihan perangkat lunak untuk sistem ini adalah agar dapat menghubungkan database lainnya tanpa merusak struktur maupun data yang terdapat didalamnya, agar memungkinkan pemakai membuat file database serta menghubungkan dengan tanpa merusak yang telah ada, juga mempertimbangkan bahwa software tersebut banyak tersedia dipasaran, adapun software yang dipilih adalah :

Tabel 2. Perangkat Lunak Yang Dibutuhkan

\begin{tabular}{|l|l|}
\hline Jenis & Kebutuhan \\
\hline Sistem Operasi & Windows 7 \\
\hline Bahasa Pemograman & PHP \\
\hline Database & Xampp Mysql \\
\hline Browser & Mozila, Chrome, Opera \\
\hline Framework / Template & Bootstrap 4.8 \\
\hline
\end{tabular}

b. Perangkat Keras

Untuk mendukung Perancangan Web ini maka untuk kebutuhan sumber daya perangkat keras disarankan dengan konfirmasi sebagai berikut :

Tabel 3. Perangkat Keras Yang Dibutuhkan

\begin{tabular}{|l|l|l|}
\hline Komponen & Minimum & Pilihan \\
\hline Processor & Pentium core 2 duo & Core i3 \\
\hline Ram & $1 \mathrm{~Gb}$ & $2 \mathrm{~Gb}$ \\
\hline Harddisk & $160 \mathrm{~Gb}$ & $250 \mathrm{~Gb}$ \\
\hline Kecepatan & $1200 \mathrm{MHz}$ & $1200 \mathrm{Mhz}$ \\
\hline Display Adapter & $189 \mathrm{Mb}$ & $1092 \mathrm{Mb}$ \\
\hline Keyboard & $101 \mathrm{Key}$ & $122 \mathrm{Key}$ \\
\hline
\end{tabular}




\section{c. Manusia}

Sumber Daya Manusia yang didalamnya menjalankan pengembangan sistem adalah seorang operator atau yang berpengalaman mengoperasikan komputer, minimal untuk mengoperasikan program itu sendiri .

\section{Tabel 5. Sumber Daya Manusia}

\begin{tabular}{|l|l|}
\hline Jenis & Kebutuhan \\
\hline Jaringan & LAN \\
\hline Sistem Operasi & Windows \\
\hline Aplikasi Komputer & Aplikasi Perkantoran \\
\hline
\end{tabular}

\section{Tampilan User (Pengguna)}

a. Tampilan Home

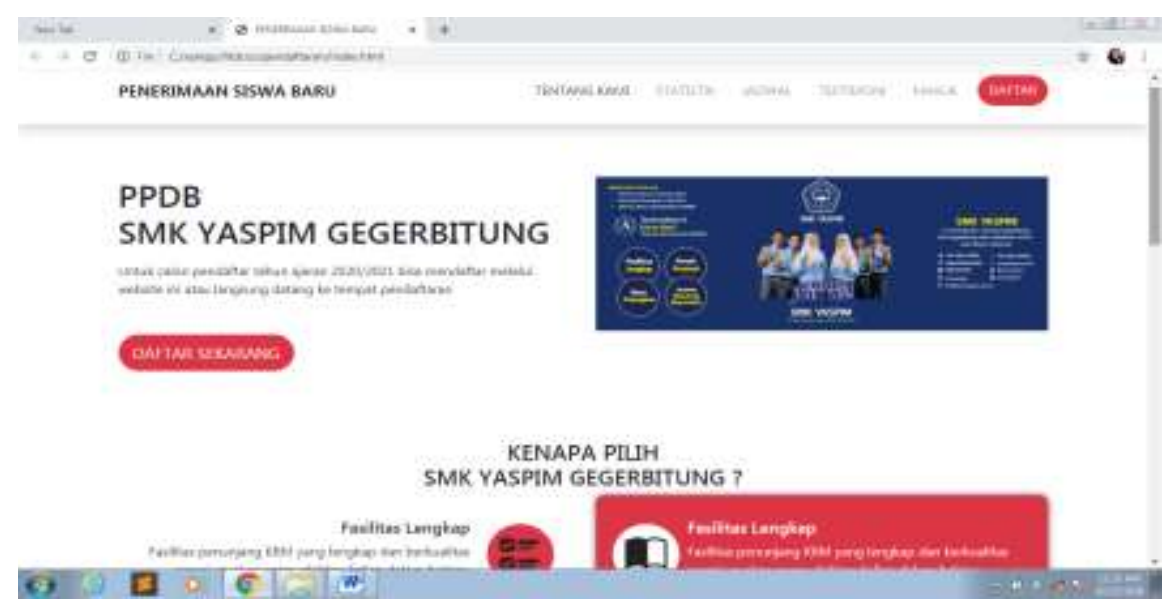

Gambar 8. Tampilan Home

b. Tampilan Registrasi

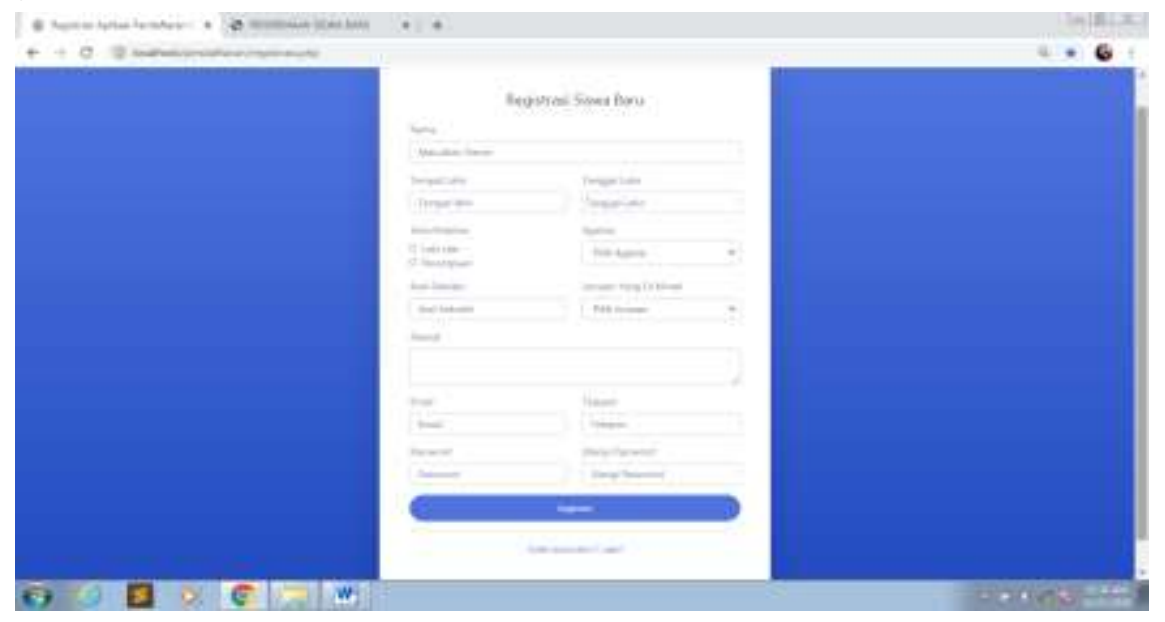

Gambar 9. Tampilan Register 


\section{c. Tampilan Login}

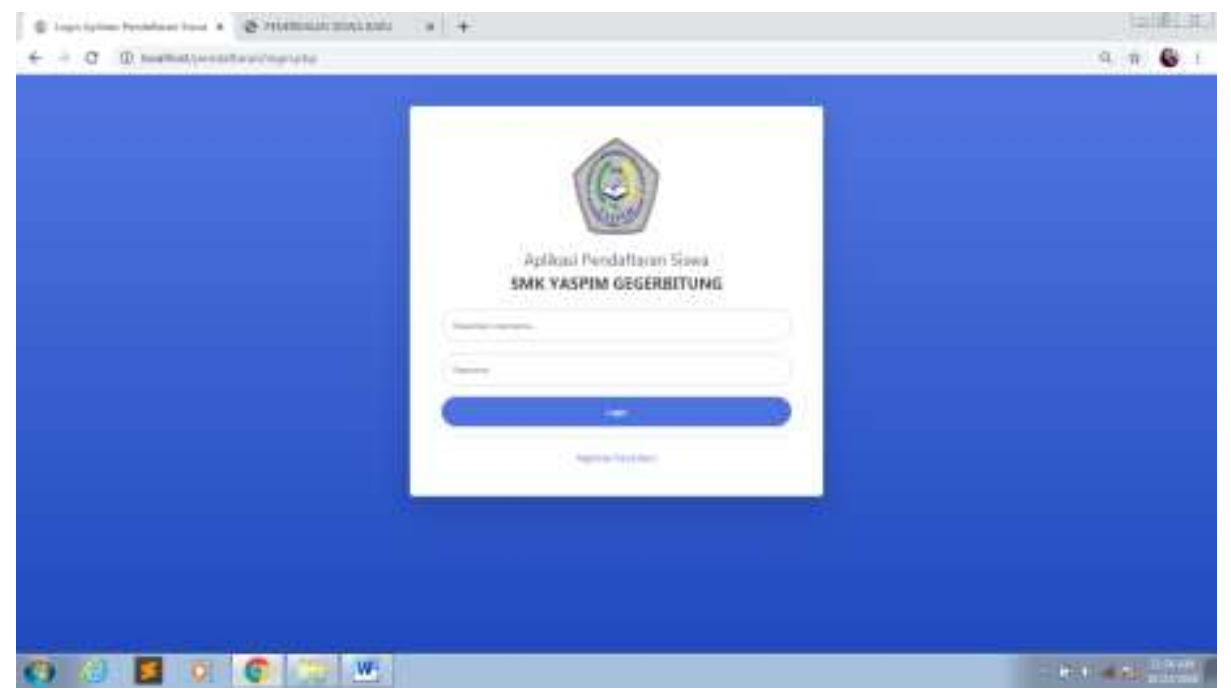

Gambar 10. Tampilan Login

\section{d. Tampilan Dashboard User}

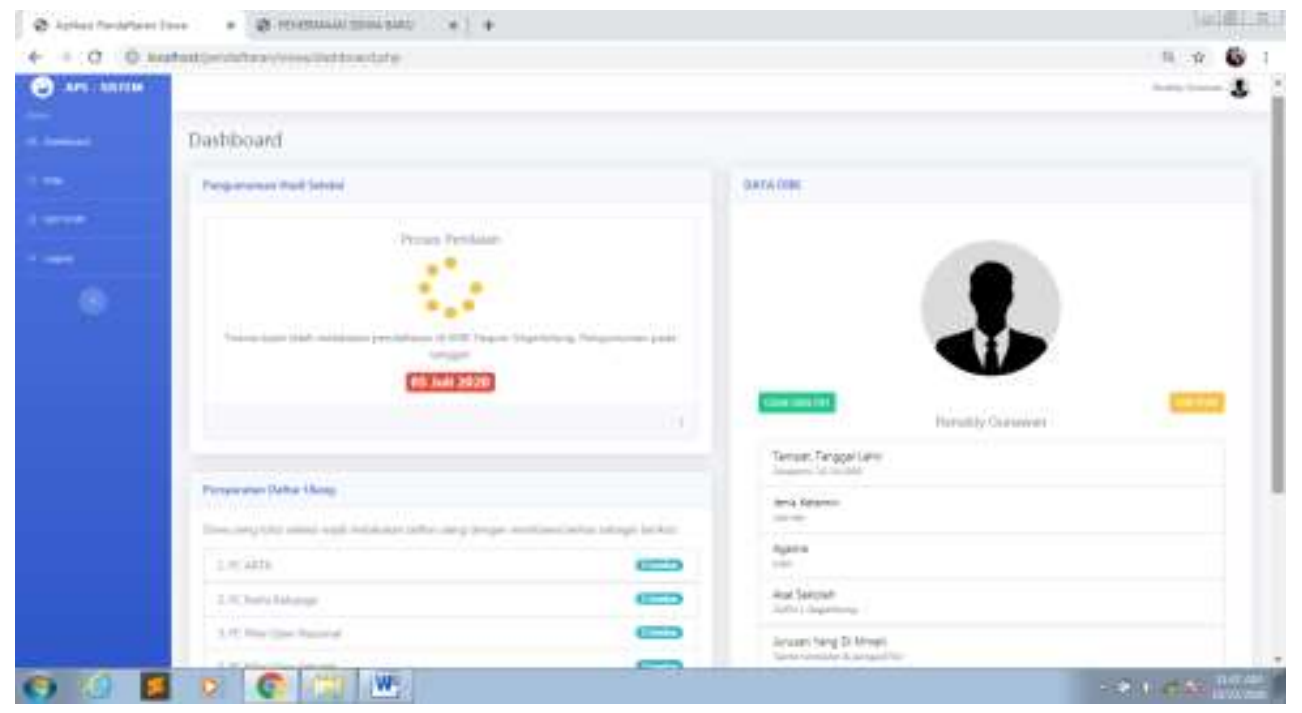

Gambar 11. Tampilan Dasboard 
e. Tampilan Edit Nilai

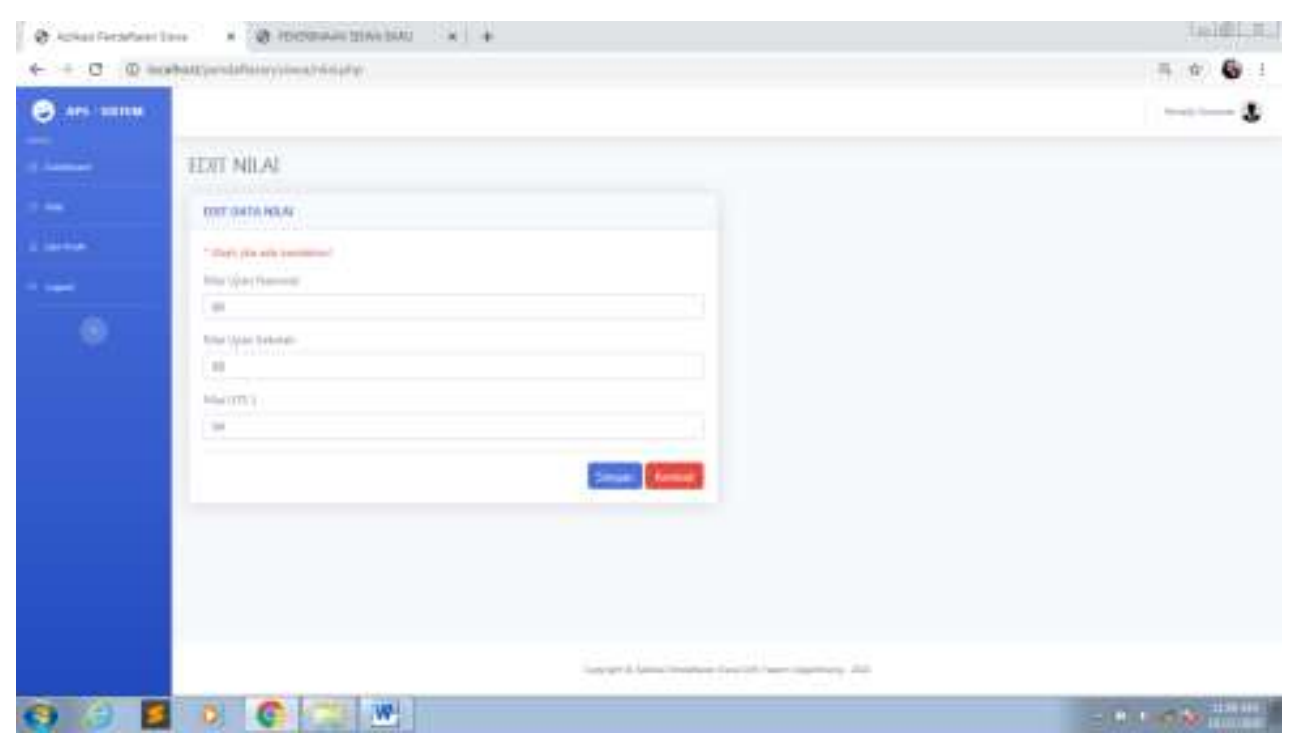

Gambar 12. Tampilan Dasboard

\section{f. Tampilan Edit Profil}

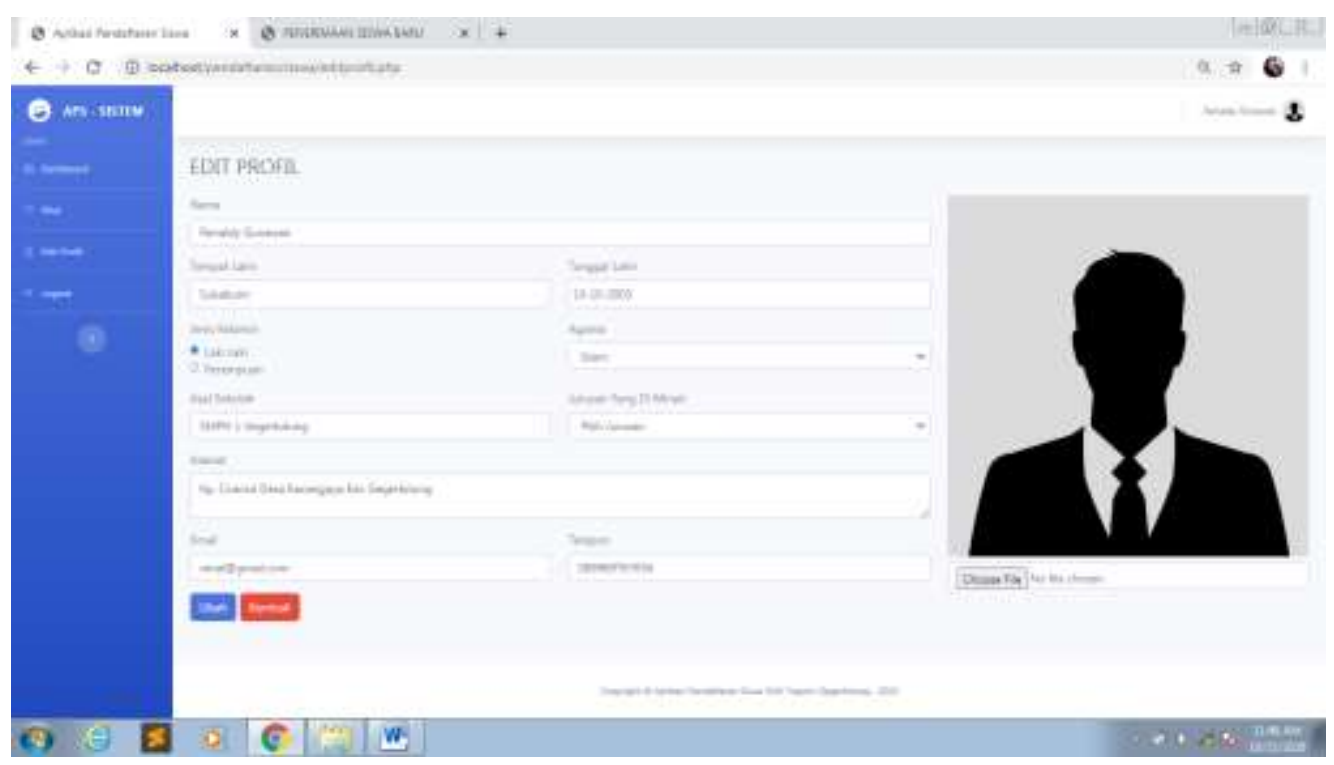

Gambar 13. Tampilan Dasboard 


\section{Tampilam Admin}

a. Tampilan Dashboard Admin

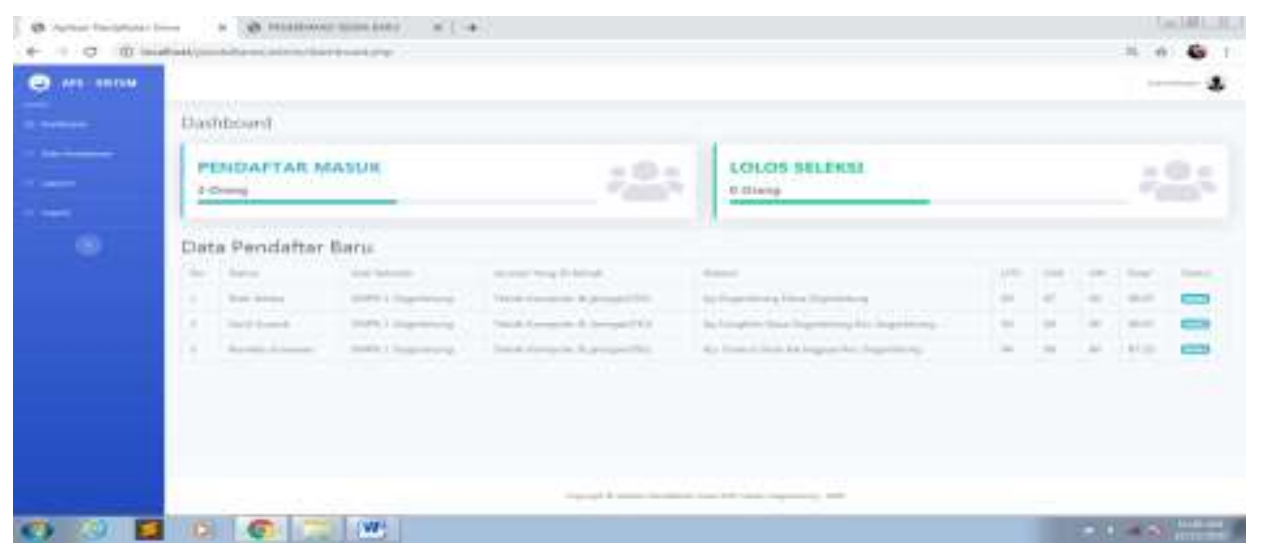

Gambar 14. Tampilan Dasboard

b. Tampilan Laporan Pendaftaran

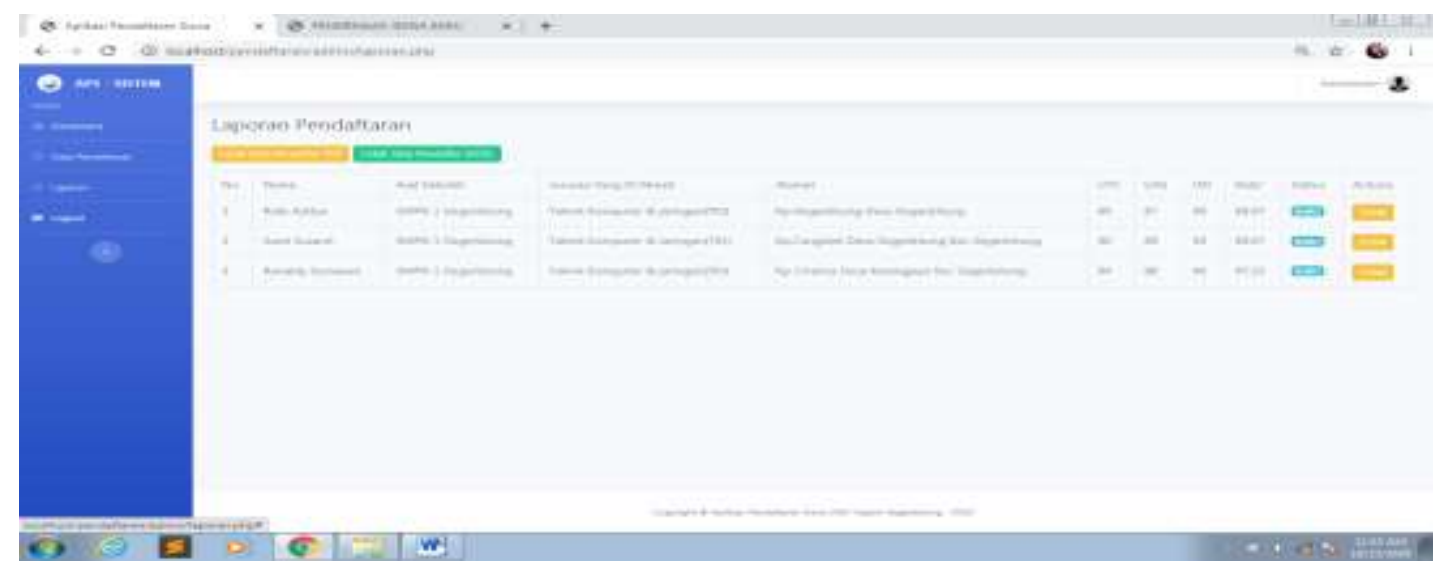

Gambar 15. Tampilan Dasboard

c. Tampilan Hasil Cetak Detail Pendaftar

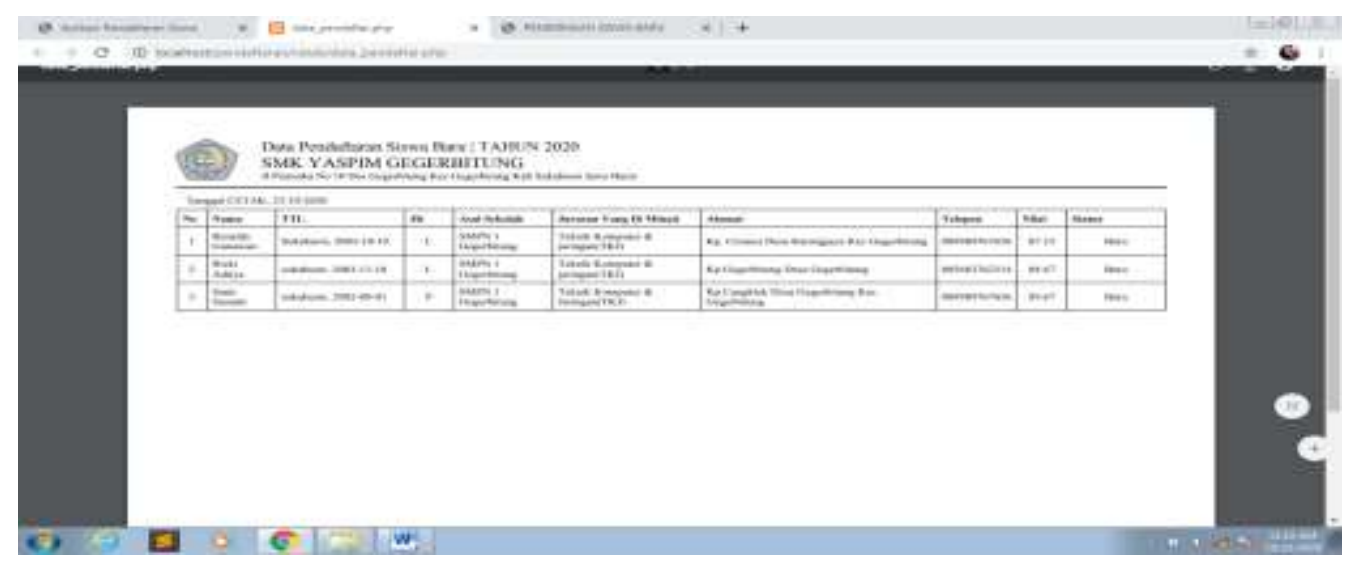

Gambar 16. Tampilan Cetak 


\section{KESIMPULAN}

Dari mulai tahapan analisis, perancangan sampai pembuatan program yang telah diuraikan pada bab sebelumnya, maka penulis dapat mengambil kesimpulan mengenai manfaat dari program aplikasi yang di buat ini di antaranya :

1. Dengan adanya sistem Aplikasi Penerimaan Siswa Baru ini diharapkan dapat lebih membantu mempermudah dalam mengelola data siswa dan siswa baru di SMK Yaspim Gegerbitung Kabupaten Sukabumi secara efektif dan efisien

2. Dengan adanya pengembangan sistem Aplikasi yang ada, maka sistem tersebut akan menjadi lebih cepat dan akurat dalam penerimaan siswa dan siswi baru di SMK Yaspim Gegerbitung Kabupaten Sukabumi.

\section{Daftar Pustaka}

[1]. Asropudin, 2013. Pengetahuan Dasar Ilmu Komputer, Yogyakarta : Andi

[2]. Bunafit. 2015. Panduan Praktis PHP \& MySql Untuk Profesional Yogyakarta: Andi Yogyakarta

[3]. Cashman, Verman, Shelly, 2015, Perancangan Aplikasi, Jakarta : PT Pustaka Binama

[4]. Daryanto. 2013. Pengetahuan Dasar Ilmu Komputer. Rama Widya. Bandung.

[5]. Fatansyah. 2015. Basis Data. Bandung : Informatika.

[6]. Hidayatullah, Priyanto \& Jauhari Khairul Kawistara. 2017. Pemrograman Web Bandung : Informatika.

[7]. Kuwayatno, Lia, 2015. Pengenalan Web Browser, Jakarta : Pustaka Media

[8]. Purnama, Suci, 2011. Penerimaan Siswa Baru, Jakarta : Pustaka Setia

[9]. Rosa A.S dan M. Shalahudin Pemodelan dan UML. 2014. Bandung : Informatika

[10]. Simarmata, 2010. Pengertian Aplikasi Web, Jakarta : PT Alex Media

[11]. W. Pramana, Hengky, 2016. Instalasi dan konfigurasi jaringan Komputer, Jakarta : Pustaka Setia 